\title{
Computational assessment of energy efficiency and hygrothermal performance of retrofitted historical building envelopes
}

\author{
V. Kočí, J. Maděra \& R. Černý \\ Department of Materials Engineering and Chemistry, \\ Faculty of Civil Engineering, Czech Technical University in Prague, \\ Czech Republic
}

\begin{abstract}
Energy efficiency and hygrothermal performance of retrofitted historical building envelopes under climatic conditions of Prague is analyzed in the paper. In order to meet the requirements on the original facade appearance of buildings belonging to architectural heritage, the retrofitting is carried out using different types of interior thermal insulation systems. The computational results indicate that hydrophilic or capillary active materials can represent a suitable material solution as they can significantly improve the energy efficiency (up to $87 \%$ in the studied cases) while their hygrothermal performance is good from a building physics point of view.

Keywords: building envelope, capillary active, hydrophilic, interior thermal insulation, computational assessment.
\end{abstract}

\section{Introduction}

Energy and sustainability represent a hard challenge in retrofitting the historical building stock. The technical solutions related to the energy efficiency on the one hand and the conservation and maintenance of architectural heritage on the other present two controversial aspects of the renovation works. Therefore, it is essential to address these two issues in such a way that the obtained result can meet the current requirements of energy efficiency and, at the same time, promote the preservation of historical buildings for future generations.

Application of additional thermal insulation systems is the simplest and most straightforward solution to the required improvement of historical buildings' 
thermal performance [1]. However, it is mostly crucial to preserve the original architectonical appearance of old facades. Therefore, the exterior thermal insulation composite systems commonly used for newly built structures can be rarely applied in these cases. For that sake, interior thermal insulation systems remain the only practical solution improving the thermal performance of buildings and meeting the requirements of preservationists at the same time.

Application of interior thermal insulation systems brings peculiarities from the point of view of building physics which are related to the accumulation of water vapor. To avoid it, many designers of interior thermal insulation systems place water vapor barrier just under the internal plaster, directly on the surface of the insulation layer so that both the insulation layer and load bearing structure are protected against water vapor penetration. Unfortunately, this solution can perform well on a theoretical level only. The problem is that in the practice it is very difficult to avoid mechanical damage of water vapor barrier placed in such an inappropriate way. In addition, even in the case that mechanical damage of the barrier is avoided, in winter period, when air ventilation in the interior is usually limited, the absence of water vapor removal can lead to undesirable increase of relative humidity and to worsening of internal microclimate. For historical buildings this is not acceptable. Therefore, other solutions based on capillary active or hydrophilic thermal insulation materials should be preferred and these are presented in this paper.

\section{Computational analysis}

Before the calculation can be started, gathering of input parameters of the mathematical model, such as the material parameters of involved materials, scheme of construction detail, initial and boundary conditions and time specifications of the simulation is required. Description of all input parameters is given in the following subchapters in more detail.

\subsection{Computer code and mathematical model}

The computational analysis was accomplished by the computer code HEMOT [2], which was developed at the Department of Materials Engineering and Chemistry, Faculty of Civil Engineering, Czech Technical University in Prague. It works on the basis of the general finite element package SIFEL [3]. In these calculations, Künzel's mathematical model for coupled heat and moisture transport in porous building materials was used [4]. It provides reliable data about heat and moisture distribution depending on time and position in a construction. The results can be then effectively used for a subsequent assessment of energy efficiency and hygrothermal performance of analyzed building envelopes.

\subsection{Scheme of construction detail}

Solid ceramic brick and sandstone were selected as representative historical building materials commonly used (not only) on the Czech territory. The load 
bearing structure in a thickness of $500 \mathrm{~mm}$ was provided from the interior side with three types of hydrophilic or capillary active thermal insulation materials $(100 \mathrm{~mm})$, namely hydrophilic mineral wool, calcium silicate and Ytong Multipor, which is thermal insulating material produced by Xella CZ. The analysed building envelope was provided with lime-cement plasters from both sides. The scheme of building envelope including thicknesses of particular layers is captured in Fig. 1.

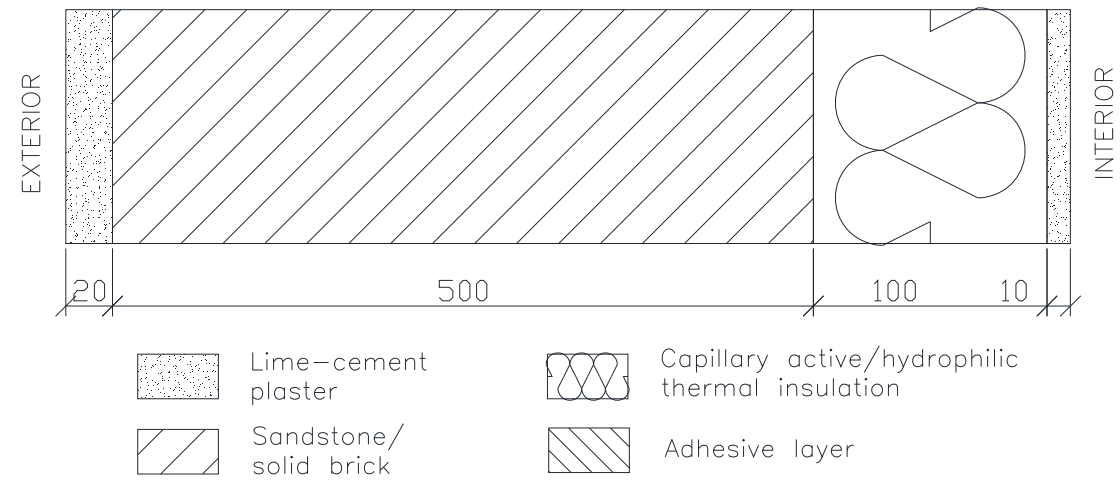

Figure 1: Scheme of analyzed construction detail.

\subsection{Material parameters}

The sandstone analysed in this paper comes from quarry Kocbeře in the Czech Republic. It is fine-grained glauconitic sandstone with massive texture. From petrological point of view it is formed by quartz (83\%), K-feldspar (2\%), muscovite, rutile, tourmaline or zircon (1\%).

All the basic physical, heat and moisture transport and storage parameters used as input data in presented calculations were measured in the laboratories of the Department of Materials Engineering and Chemistry, Faculty of Civil Engineering, Czech Technical University in Prague [5-10] according to the methodology presented in [11]. The moisture diffusivity of calcium silicate was calculated from moisture profiles presented in [12] using inverse analysis with smoothing splines [13]. The gathered laboratory data are summarized in Tables 1

Table 1: $\quad$ Material characteristics - part I.

\begin{tabular}{|c|c|c|c|}
\hline Parameter & Sandstone & Solid ceramic brick & Lime-cement plaster \\
\hline$\rho\left[\mathrm{kg} \mathrm{m}^{-3}\right]$ & 2228 & 1831 & 1244 \\
\hline$\psi[\%]$ & 16.1 & 27.9 & 49.8 \\
\hline$c\left[\mathrm{~J} \mathrm{~kg}^{-1} \mathrm{~K}^{-1}\right]$ & $754-1023$ & $825-1254$ & $1054-1592$ \\
\hline$\mu[-]$ & $7.4-12.7$ & $6.3-22.1$ & $5.5-7.5$ \\
\hline$\lambda_{d r y}\left[\mathrm{~W} \mathrm{~m}^{-1} \mathrm{~K}^{-1}\right]$ & 3.530 & 0.590 & 0.296 \\
\hline$\lambda_{\text {sat }}\left[\mathrm{W} \mathrm{m}^{-1} \mathrm{~K}^{-1}\right]$ & 5.210 & 1.735 & 0.943 \\
\hline$\kappa_{\text {app }}\left[\mathrm{m}^{2} \mathrm{~s}^{-1}\right]$ & $1.06 \mathrm{e}-7$ & $3.16 \mathrm{e}-7$ & $8.30 \mathrm{e}-9$ \\
\hline$w_{\text {hyg }}\left[\mathrm{m}^{3} \mathrm{~m}^{-3}\right]$ & 0.0035 & 0.0020 & 0.0144 \\
\hline
\end{tabular}


and 2, where the following symbols are used: $\rho$ - bulk density $\left[\mathrm{kg} / \mathrm{m}^{3}\right]$, $\psi$ - porosity [\%], $c$ - specific heat capacity $[\mathrm{J} / \mathrm{kgK}], \mu$ - water vapor diffusion resistance factor [-], $\lambda$ - thermal conductivity $[\mathrm{W} / \mathrm{mK}], \kappa_{\text {app }}-$ apparent moisture diffusivity $\left[\mathrm{m}^{2} / \mathrm{s}\right]$, $w_{h y g}-$ hygroscopic moisture content by volume $\left[\mathrm{m}^{3} / \mathrm{m}^{3}\right]$.

Table 2: $\quad$ Material characteristics - part II.

\begin{tabular}{|c|c|c|c|}
\hline Parameter & Hydrophilic mineral wool & Calcium silicate & Multipor \\
\hline$\rho\left[\mathrm{kg} \mathrm{m}^{-3}\right]$ & 70 & 268 & 125 \\
\hline$\psi[\%]$ & 96.9 & 89.5 & 94.2 \\
\hline$c\left[\mathrm{~J} \mathrm{~kg}^{-1} \mathrm{~K}^{-1}\right]$ & 810 & 1120 & $2230-3500$ \\
\hline$\mu[-]$ & $1.2-2.4$ & $2.85-6.72$ & $1.9-10.9$ \\
\hline$\lambda_{\text {dry }}\left[\mathrm{W} \mathrm{m}^{-1} \mathrm{~K}^{-1}\right]$ & 0.037 & 0.070 & 0.047 \\
\hline$\lambda_{\text {sat }}\left[\mathrm{W} \mathrm{m}^{-1} \mathrm{~K}^{-1}\right]$ & 0.790 & 0.700 & 0.166 \\
\hline$\kappa_{a p p}\left[\mathrm{~m}^{2} \mathrm{~s}^{-1}\right]$ & $8.50 \mathrm{e}-6$ & $2.30 \mathrm{e}-7$ & $3.26 \mathrm{e}-9$ \\
\hline$w_{h y g}\left[\mathrm{~m}^{3} \mathrm{~m}^{-3}\right]$ & 0.00026 & 0.066 & 0.0078 \\
\hline
\end{tabular}

\subsection{Boundary conditions and time interval of simulation}

Constant values of relative humidity $(55 \%)$ and temperature $\left(21^{\circ} \mathrm{C}\right)$ were used as boundary conditions on the interior side of the analyzed building envelopes [14]. In order to obtain as realistic results as possible, dynamic climatic conditions in the form of test reference year for Prague were applied on the exterior side. A test reference year contains long term average values of temperature, relative humidity, wind direction and velocity, rainfalls and several kind of sun radiation. These data were obtained using Meteonorm software [15].

The results of hygrothermal simulations have to be evaluated after a certain period of time which is necessary for the properties to achieve a kind of dynamic equilibrium, as the hygric and thermal properties of building materials used as input parameters depend on the state variables such as temperature or moisture content. Therefore, the results of hygrothermal performance presented in this paper will be related to the tenth year of simulation which is, according to our previous experience, long enough for a development of cyclic hygrothermal behavior.

\subsection{Energy efficiency calculations}

The energy efficiency calculated in this paper is related to the tenth year of simulation, expressing the annual amount of heat transported through the envelope. It is calculated as the time integral of heat flux according to the relation 


$$
Q=\int_{1 J a n}^{31 D e c} q(t) d t
$$

where $Q$ denotes the energy transferred through a square meter of the envelope per annum $\left[\mathrm{kWh} / \mathrm{m}^{2}\right.$ envelopea $]$ and $q(t)$ is heat flux as a function of time $\left[\mathrm{W} / \mathrm{m}^{2}\right.$ envelope $]$ in a boundary element of the building envelope cross-section. It is calculated as

$$
q=-\lambda(w) \frac{d T}{d x},
$$

where $\lambda(w)$ is thermal conductivity depending on moisture content [W/mK], $d T$ is difference between temperatures of two nodes defining the boundary element [K] and $d x$ is size of the element [m].

In order to quantify the contribution of retrofitting the envelope to the energy efficiency, also reference envelope without thermal insulation was analyzed.

\section{Computational results and discussion}

The results of computational simulations were obtained in the form of hourly nodal values of temperature and moisture content. These data were subsequently used for the construction of moisture profiles and for the calculation of energy efficiency. All the results are summarized in the subsequent set of figures and tables. Because of the large number of figures and their partial similarity only the representative ones are chosen, the rest of them is only described in the text. In the figures depicting the moisture or temperature profiles in a building envelope, the position $0 \mathrm{~mm}$ always indicates the interior side, while the position $630 \mathrm{~mm}$ marks the exterior.

\subsection{Hygrothermal performance}

According to the computational results, the differences in temperature profiles of the particular building envelopes are not significant. It can be caused by very similar thermal properties of thermal insulating materials and by the fact that the insulation is placed on the interior side of building envelopes, thus the exposure to weather conditions leading to worsening of thermal insulating capabilities is avoided.

The highest temperature differences can be found on the interface between load bearing material and thermal insulation. For example in Fig. 2 showing temperature profiles of retrofitted brick based building envelopes on January 15, the difference is only $3.27^{\circ} \mathrm{C}$. The same can be spoken about the summer period (represented by July 15), as it is seen in Fig. 3 capturing temperature profiles of sandstone building envelopes provided with interior thermal insulation. In this case, the difference is only about $0.24^{\circ} \mathrm{C}$. 


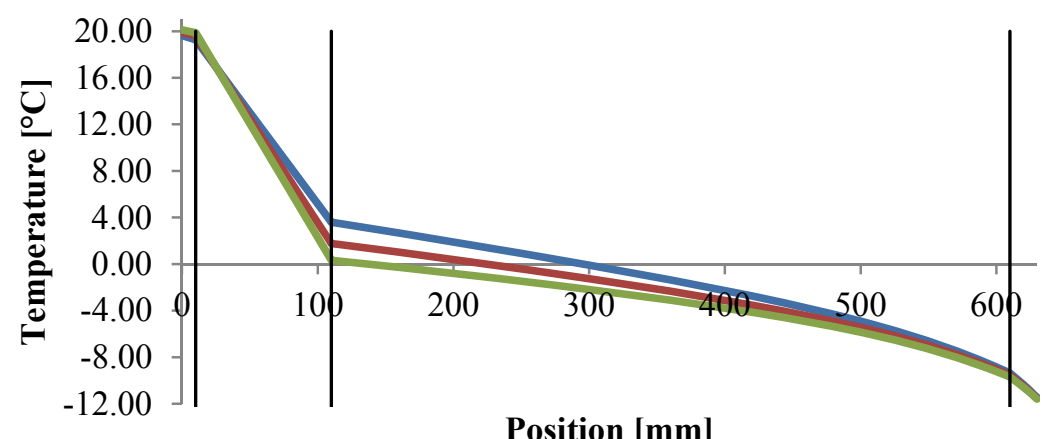

Calcium-silicate $\longrightarrow$ Multipor $\longrightarrow$ Hydrophilic mineral wool

Figure 2: $\quad$ Temperature profile, solid brick building envelope, January 15 .

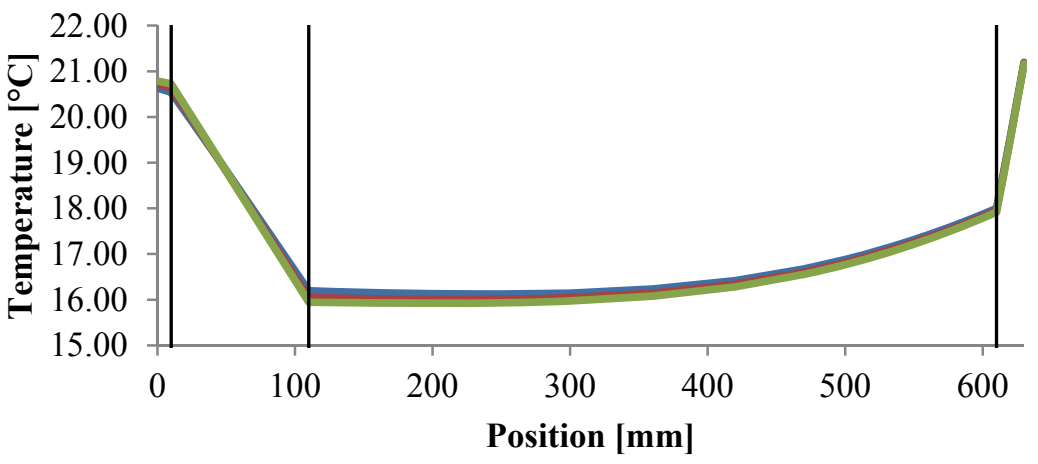

$\longrightarrow$ Calcium-silicate $\longrightarrow$ Multipor $\longrightarrow$ Hydrophilic mineral wool

Figure 3: Temperature profile, sandstone building envelope, July 15.

A comparison of temperature vs. time functions on the material interface between sandstone and thermal insulation is shown in Fig. 4. The data showed in the graph only confirm the minimal temperature differences found for the particular building envelopes. 


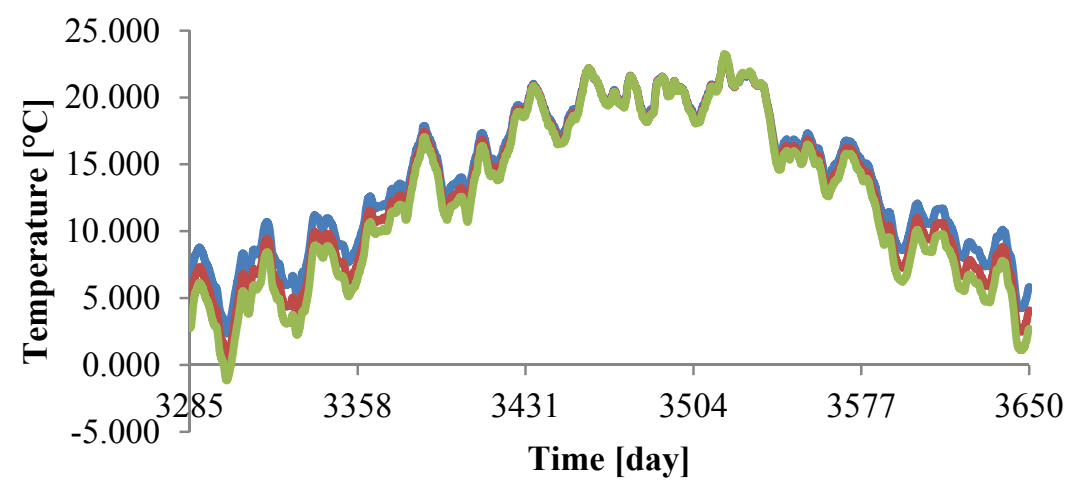

Calcium silicate $\longrightarrow$ Multipor $\longrightarrow$ Hydrophilic mineral wool

Figure 4: Temperature vs. time functions, sandstone building envelope.

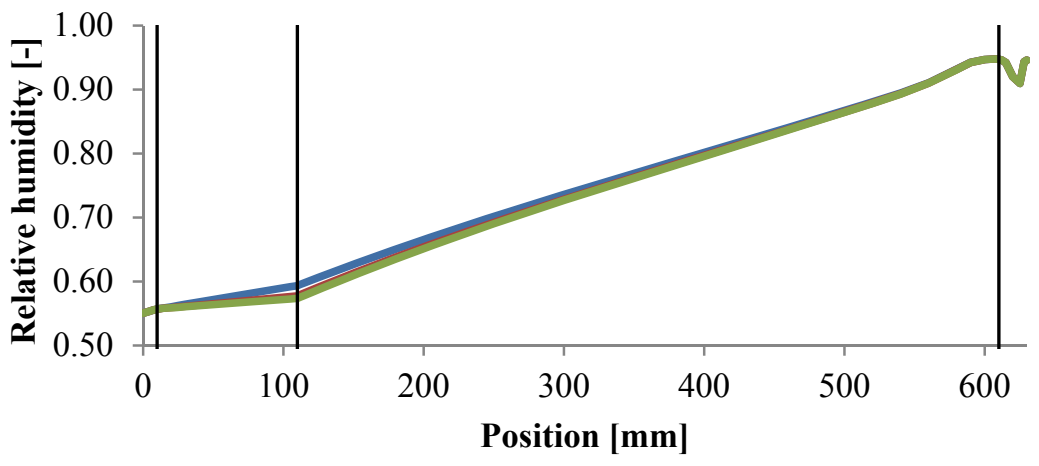

Calcium silicate $\longrightarrow$ Multipor $\longrightarrow$ Hydrophilic mineral wool

Figure 5: Relative humidity profile, solid brick building envelope, January 15.

Besides the temperature profiles, a placement of thermal insulation on the interior side of a building envelope leads to the minimization of differences between the relative humidity profiles as well. This phenomenon cannot be seen in the case of external thermal insulation systems, because thermal insulation placed on the exterior side serves as an effective rain protection; thus it can significantly reduce the amount of moisture income, depending on its type and moisture transport and storage properties. However, in the case of internal thermal insulation systems, a thermal insulation does not exhibit such effect. Therefore, very similar relative humidity profiles of all investigated building envelopes can be seen in Figs 5 and 6, which show relative humidity profile of solid brick building envelope on January 15 (Fig. 5) and relative humidity profile 
of sandstone building envelope on July 15 (Fig. 6). According to Fig. 7, the relative humidity difference on the interface between thermal insulation and sandstone reaches only $1.97 \%$. Furthermore, relative humidity in the winter period in the external layers of building envelope can reach very high values (see Fig. 5) which raises the risk of moisture damage.

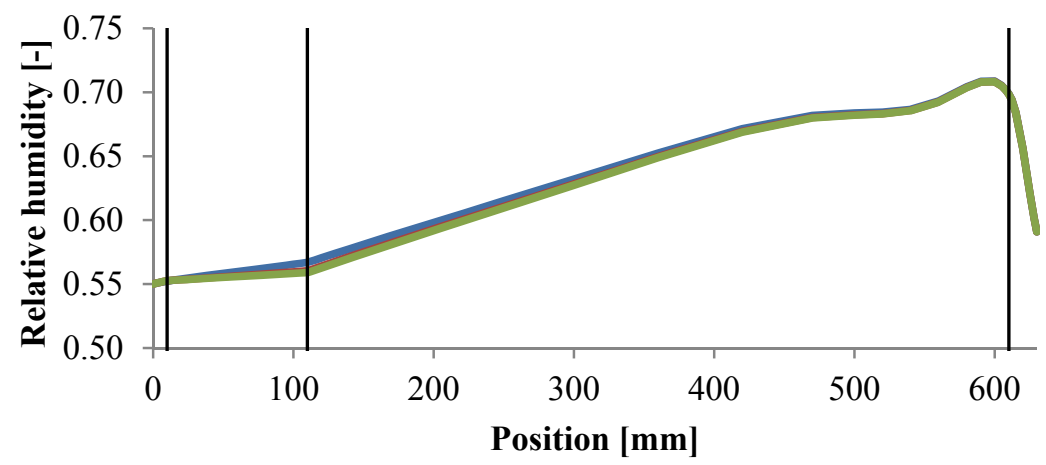

Calcium silicate $\longrightarrow$ Multipor $\longrightarrow$ Hydrophilic mineral wool

Figure 6: Relative humidity profile, sandstone building envelope, July 15.

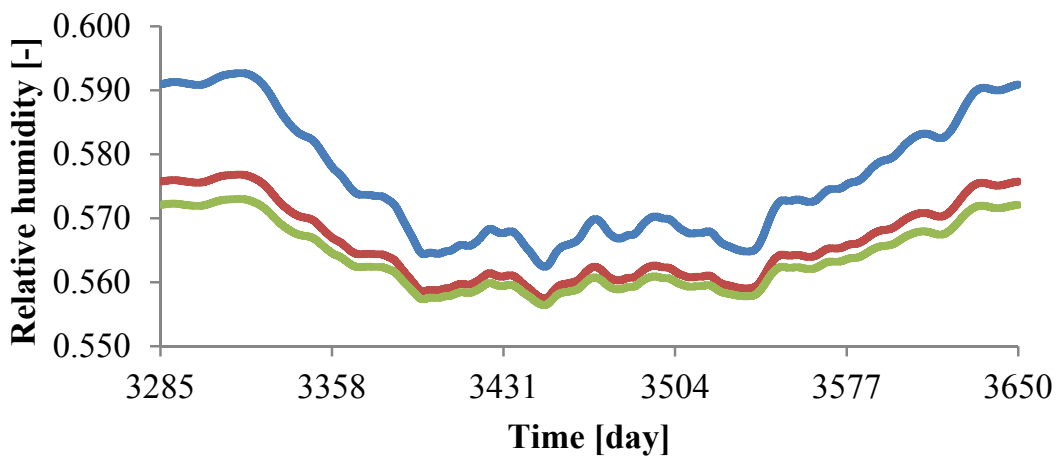

Calcium silicate $\longrightarrow$ Multipor $\longrightarrow$ Hydrophilic mineral wool

Figure 7: Relative humidity vs. time functions, sandstone building envelope.

\subsection{Energy efficiency}

The energy efficiency of the analysed building envelopes was calculated on the interior side because of the more steady values of heat fluxes which are not affected by the climatic conditions as much as on the exterior side. 
Figures 8 and 9 depict heat fluxes on interior side of solid brick (Fig. 8) and sandstone building envelope (Fig. 9). As indicated by the lowest values of heat fluxes in both cases, the best results are achieved when hydrophilic mineral wool is applied. This fact is given by its lowest dry state value of thermal conductivity (see Table 2) among all the analysed thermal insulations. The highest water saturated value of thermal conductivity of hydrophilic mineral wool among all

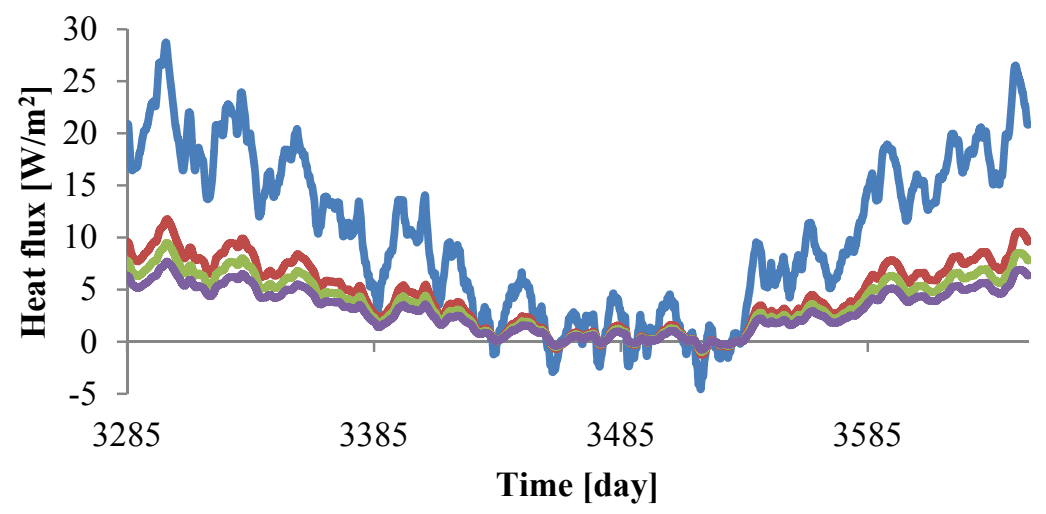

Without thermal insulation - Calcium silicate
Multipor

Figure 8: Heat flux vs. time functions, solid brick building envelope.

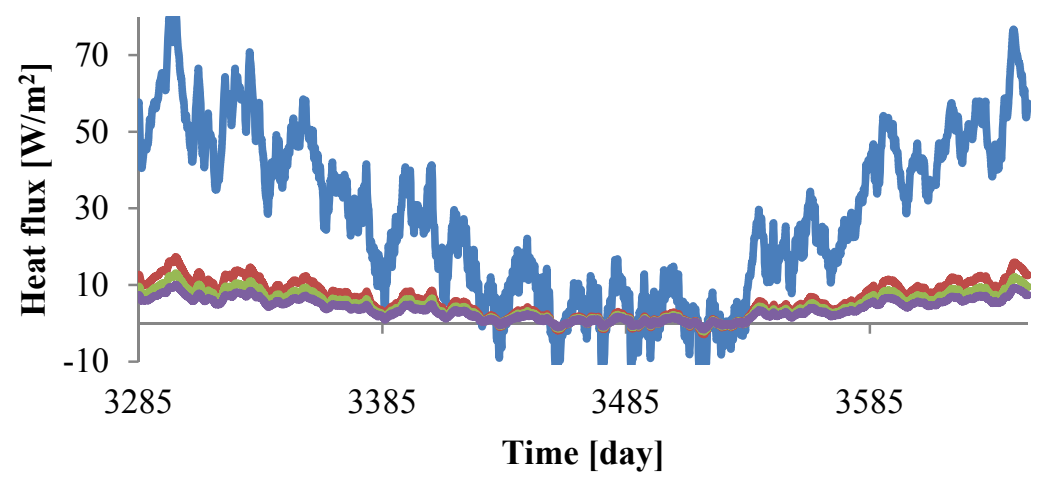

- Without thermal insulation - Calcium silicate
Multipor

Figure 9: Heat flux vs. time functions, sandstone building envelope. 
the insulations did not play any substantial role here because thanks to its position on the interior side the moisture content was kept permanently low, thus thermal insulating abilities were reliably preserved.

The values of heat fluxes through investigated envelopes are much higher in the case of sandstone building envelope because the thermal insulating capability of sandstone in dry state is up to six times worse than for the solid brick.

Based on the heat flux vs. time functions the energy efficiency of the particular building envelopes was calculated. It expresses the annual amount of heat transported from the interior to the exterior through one square meter of the envelope. The results are summarized in Table 3. They confirm that a presence of thermal insulation significantly contributes to the improvement of energy performance of the analyzed building envelopes. For example, the calcium silicate plates in a thickness of $100 \mathrm{~mm}$ applied on sandstone building envelope can reduce the energy need from $242.26 \mathrm{kWh} / \mathrm{m}^{2}$ a to $53.25 \mathrm{kWh} / \mathrm{m}^{2} \mathrm{a}$ which represents an improvement of approximately $78 \%$. The highest improvements, up to $87.17 \%$, are reached when hydrophilic mineral wool is used.

Table 3: Energy efficiency summary.

\begin{tabular}{|l|c|c|c|c|}
\hline \multirow{2}{*}{} & \multicolumn{2}{|c|}{ Solid brick } & \multicolumn{2}{c|}{ Sandstone } \\
\cline { 2 - 5 } & $\begin{array}{c}Q \\
{\left[\mathrm{kWh} / \mathrm{m}^{2} \mathrm{a}\right]}\end{array}$ & Improvement $[\%]$ & $\begin{array}{c}Q \\
{\left[\mathrm{kWh} / \mathrm{m}^{2} \mathrm{a}\right]}\end{array}$ & $\begin{array}{c}\text { Improvement } \\
{[\%]}\end{array}$ \\
\hline $\begin{array}{l}\text { Without thermal } \\
\text { insulation }\end{array}$ & 88.61 & - & 242.56 & - \\
\hline Calcium silicate & 38.53 & 56.52 & 53.25 & 78.05 \\
\hline Multipor & 31.26 & 64.72 & 40.29 & 83.39 \\
\hline $\begin{array}{l}\text { Hydrophilic } \\
\text { mineral wool }\end{array}$ & 25.44 & 71.29 & 31.12 & 87.17 \\
\hline
\end{tabular}

\section{Conclusions}

Computational analysis of hygrothermal performance and energy efficiency of retrofitted historical building envelopes was performed in this paper. Sandstone and solid ceramic brick were chosen as representative historical building materials and the envelopes were provided from the interior side with calcium silicate, Multipor and hydrophilic mineral wool, in order to preserve the original historical facade which is often required by conservationists. The simulations were performed under dynamic climatic conditions in Prague represented by a test reference year.

The results of computational analysis indicated that capillary active or hydrophilic insulation materials can be the proper choice for interior thermal insulation of historical buildings, as they significantly improved energy efficiency of the envelopes while the original appearance of the facades remained unchanged. It was also proven that hydrophilic or capillary active materials applied on the interior side of the envelopes did not cause any accumulation of moisture in the envelope. Therefore, the common problems 
related to the interior thermal insulations provided with water vapor barrier were eliminated. On the other hand, it may be necessary to provide some additional solution to protect the external facade against rain and subsequent liquid water penetration.

Among the investigated thermal insulation materials, the best results were obtained when hydrophilic mineral wool was applied. In this case, the energy transfer through the sandstone building envelope was reduced by $87.17 \%$ and for the solid brick building envelope it was $71.29 \%$. However, the other analysed thermal insulation materials, namely calcium silicate and Multipor, evinced very good hygrothermal and energy performance as well.

\section{Acknowledgement}

This research has been supported by the Czech Science Foundation, under project No P105/12/G059.

\section{References}

[1] Zagorakis, J., Zavadskas, E. K., Turskis, Z., Burinskiene, M., Blumberga, A., Blumberga, D. Thermal insulation alternatives of historic brick buildings in Baltic Sea Region. Energy and Buildings, 78, pp. 35-42, 2014.

[2] Černý, R. Complex System of Methods for Directed Design and Assessment of Functional Properties of Building Materials: Assessment and Synthesis of Analytical Data and Construction of the System, CTU Prague, 2010.

[3] Kruis, J. Koudelka, T., Krejčí, T. Efficient computer implementation of coupled hydro-thermo-mechanical analysis. Mathematics and Computers in Simulation, 80, pp. 1578-1588, 2010.

[4] Künzel, H. M., Simultaneous Heat and Moisture Transport in Building Components, Ph. D. Thesis. IRB Verlag, Stuttgart, 1995.

[5] Kočí, V., Maděra, J., Fořt, J., Žumár, J., Pavlíková, M., Pavlík, Z., Černý, R. Service Life Assessment of Historical Building Envelopes Constructed Using Different Types of Sandstone: A Computational Analysis Based on Experimental Input Data. The Scientific World Journal, 2014, p. 12, 2014, doi:10.1155/2014/802509

[6] Roels, S., Carmeliet, J., Hens, H., Adan, O., Brocken, H., Černý, R., Pavlík, Z., Hall. C., Kumaran, K., Pel, L., Plagge, R. Interlaboratory comparison of hygric properties of porous building materials. Journal of Thermal Envelope \& Building Science, 27, pp. 307-325, 2004.

[7] Jerman, M., Černý, R. Effect of moisture content on heat and moisture transport and storage properties of thermal insulation materials. Energy and Buildings, 53, pp. 39-46, 2012.

[8] Č́áchová, M., Koňáková, D., Vejmelková, E., Keppert, M., Polozhiy, K., Černý, R. Heat and water vapor transport properties of selected commercially produced plasters. Advanced Material Research, 982, pp. 90-93, 2014. 
[9] Čáchová, M., Koňáková, D., Vejmelková, E., Keppert, M., Polozhiy, K., Černý, R. Pore structure and thermal characteristics of clay bricks. Advanced Material Research, 982, pp. 104-107, 2014.

[10] Pavlík, Z., Pavlíková, M., Černý, R. Experimental analysis of material properties of historical ceramic bricks and their potential current replacement. In: Proceedings of $14^{\text {th }}$ International Conference on Studies, Repairs and Maintenance of Heritage Architecture 2015. Southampton: WIT Press, 2015.

[11] Černý, R., (ed). Complex System of Methods for Directed Design and Assessment of Functional Properties of Building Materials and Its Application, CTU Prague: Prague, 2013.

[12] Roels, S., Carmeliet, J., Hens, H., Adan, O., Brocken, H., Černý, R., Pavlík, Z., Ellis, A.T., Hall. C., Kumaran, K., Pel, L., Plagge, R. A comparison of different techniques to quantify moisture content profiles in porous building materials. Journal of Thermal Envelope \& Building Science, 27, pp. 261-276, 2004.

[13] Kočí, J., Kočí, V., Ďurana, K., Maděra, J., Černý, R. Determination of moisture-dependent moisture diffusivity using smoothed experimental data. $11^{\text {th }}$ International Conference of Numerical Analysis and Applied Mathematics (ICNAAM), AIP Conference Proceedings, 1558, pp. 960-963, 2013.

[14] CSN 73 0540-2 Thermal Protection of Buildings - Part 2: Requirements, Czech Office for Standards, Metrology and Testing, Prague, 2011.

[15] Meteonorm Version 6, software version 6.1.0.20 of April 2010, METEOTEST, Switzerland, 2010. 